\title{
ERRATUM
}

\section{A cell-cell communication signal integrates quorum sensing and stress response}

Jasmine Lee, Jien Wu, Yinyue Deng, Jing Wang, Chao Wang, Jianhe Wang, Changqing Chang, Yihu Dong, Paul Williams \& Lian-Hui Zhang

Nat. Chem. Biol. 9, 339-343 (2013); published online 31 March 2013; corrected after print 12 April 2013

In the version of this article initially published online, the IQS structure used in Figure $2 \mathrm{c}$ and in the graphical abstract was incorrect. The error has been corrected for the PDF and HTML versions of this article.

\section{CORRIGENDUM}

\section{Regulation of nuclear PKA revealed by spatiotemporal manipulation of cyclic AMP}

Vedangi Sample, Lisa M DiPilato, Jason H Yang, Qiang Ni, Jeffrey J Saucerman \& Jin Zhang

Nat. Chem. Biol. 8, 375-382 (2012); published online 26 February 2012; corrected after print 19 April 2013

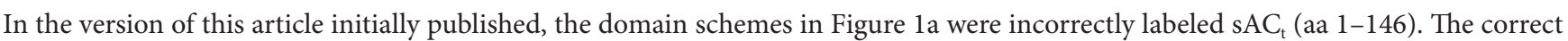
text is $\mathrm{sAC}_{\mathrm{t}}$ (aa 1-469). The error has been corrected in the HTML and PDF versions of the article.

\section{CORRIGENDUM}

\section{The catalytic center of ferritin regulates iron storage via Fe(II)-Fe(III) displacement}

Kourosh Honarmand Ebrahimi, Eckhard Bill, Peter-Leon Hagedoorn \& Wilfred R Hagen

Nat. Chem. Biol. 8, 941-948 (2012); published online 23 September 2012; corrected after print 19 April 2013

In the version of this article initially published, the units $\left(\mathrm{kJ} \mathrm{mol}^{-1}\right)$ associated with the $\Delta H$ values reported in Table 1 were inadvertently omitted. The error has been corrected in the HTML and PDF versions of the article.

\section{CORRIGENDUM}

\section{ATP-competitive inhibitors block protein kinase recruitment to the Hsp90-Cdc37 system}

Sigrun Polier, Rahul S Samant, Paul A Clarke, Paul Workman, Chrisostomos Prodromou \& Laurence H Pearl

Nat. Chem. Biol. 9, 307-312 (2013); published online 17 March 2013; corrected after print 19 April 2013

In the version of this article initially published, the authors wrote, "we first treated BT474 human breast cancer cells with the clinically approved ATP-competitive tyrosine kinase inhibitor lapatinib and found that this resulted in the displacement of Cdc37 and Hsp90 from the target kinase ErbB2," which implied that lapatinib promoted dissociation of ErbB2 from both Cdc37 and Hsp90, but the data for ErbB2 showed complete displacement of Cdc37 but not Hsp90. The error has been corrected in the HTML and PDF versions of the article. 